\title{
Weak-Form Efficiency Vs Semi-Strong Form Efficiency in Price Discovery: an Application to International Black Tea Markets
}

\author{
K.A.S.D.B. Dharmasena and David A. Bessler*
}

\begin{abstract}
In this paper we study a fundamental issue related to the efficient price discovery process using time series data from seven international black tea markets. The major question studied is as follows: Is the price discovery process in black tea markets efficient? We use two statistical techniques as engines of analysis. First, we use time series methods to capture regularities in time lags among price series. Second, we forecast the tea prices in each market using the time series model we estimated followed by a comparison of the forecast with the forecasts from the random-walk (naïve) model. Weekly time series data on black tea prices from seven markets around the world are studied using time series methods. The study follows two paths. We study these prices in a common currency, the US dollar. We also study prices in each country's local currency. Results from unit root tests suggest that prices from three Indian markets are not generated through random-walk like behavior. We conclude that the Indian markets are not weak-form efficient. However, prices from all non-Indian markets cannot be distinguished from random-walk like behavior. These latter markets are weak-form efficient. A Vector Autoregressions (VARs) on the non-Indian markets are studied in local currency and in US dollars. We use Theil's U-statistic to test the forecasting ability of the VAR models. We find that for most markets in either dollars or in local currencies, that a random walk forecast outperforms the VAR generated forecasts. This last result suggests the non-Indian markets are both weak-form and semi-strong form efficient.
\end{abstract}

\footnotetext{
* The authors are, affiliated to Department of Agricultural Economics and Business Management, Faculty of Agriculture, University of Peradeniya and Department of Agricultural Economics, Texas A\&M University, College Station, USA, respectively.
} 


\section{Introduction}

Black tea is traded primarily (about 80percent) in spot markets. These markets are located mainly in the following countries: Sri Lanka (Colombo), India (Calcutta, Coimbatore, Cochin, Guwahati, Coonoor, and Siliguri), Bangladesh (Chittagong), Indonesia (Jakarta), Kenya (Mombasa) and Malawi $(\text { Limbe })^{1}$. Tea prices are quoted in each of these markets on at least a weekly basis. These quotes are prices per kilogram. They reflect demand for and supply of tea and different quality characteristics. Prices may also reflect government interventions. Governments use trade policy instruments such as export taxes, import tariffs, and import quotas in apparent attempts to influence the price and/or consumption of tea. Such regulations may introduce inefficiencies into the tea market, which in turn may give false signals to producers in future periods.

Due to the above disparity in prices and the possible absence of an efficient market for tea (tea trade is influenced by government trade policy in importing/exporting countries), tea producers and consumers may be adversely affected. The general problem addressed in this study is to determine whether black tea markets are efficient in terms of price discovery.

In this paper we seek to answer questions of efficiency of price discovery among 7 black tea auction markets in the world. The study considers weekly prices over the period December 1999 through June 2002. We use two statistical methods as dual engines of analysis. First, we use time series methods to capture regularities in time lags among the 7 price series. Second, we use the model estimated (a vector autoregression or an error correction model) to forecast prices of each market. Finally, we investigate whether these forecasts beat the random-walk (naïve) model.

This paper is organized as follows. First we provide an introduction to the study along with a brief description of the demand, supply, exports and imports of black tea. This is followed by a description of the status of the black tea price today and a brief discussion of the auction centers considered in the study. The next section explains the modeling framework used and offers a description of the data used in the study. The last two sections give a narrative on the results obtained from the analysis, a discussion on findings and their implications on black tea auction markets.

\footnotetext{
${ }^{1}$ Auction centers are located in cities in parentheses in the respective country
} 


\section{World Black Tea Economy}

There are seven major black tea producing countries in the world. They are: Sri Lanka, India, Malawi, Kenya, Indonesia, Tanzania and Zimbabwe. Turkey, Argentina, Iran, Nepal and Bangladesh also produce black tea, but in smaller numbers relative to the major countries. Black tea is traded in several auction centers located in different parts of the world. They are Sri Lanka (Colombo), six auctions in India (Calcutta, Coimbatore, Cochin, Guwahati, Coonoor, and Siliguri), Bangladesh (Chittagong), Indonesia (Jakarta), Kenya (Mombasa) and Malawi (Limbe).

The Food and Agricultural Organization (FAO) of the United Nations has projected demand, supply and trade of black tea for the year 2005 based on the most recent data available on black tea production, consumption, population and income growth, and trade.

World black tea production is projected to increase from the 199395 average of 1.97 million $\mathrm{mt}$ to 2.7 million $\mathrm{mt}$ in 2005, an annual average growth rate of 2.8 percent. In 1999 the world black tea supply moved well ahead of demand for the first time since 1993, which created an obvious potential for an impact on tea prices. Sri Lanka and Kenya continue to lead the black tea export market (FAO, 2000).
World black tea consumption is projected to increase from 1.97 million $\mathrm{mt}$ in 1993-95 to 2.67 million mt by 2005, an annual growth rate of 2.8 percent (FAO, 2000). The reduction of import tariffs by these countries and declining prices as a result could have a more noticeable positive effect on consumption (FAO, 2000).

In developed countries, including countries in transition, black tea consumption is expected to increase more moderately. Consumption in the European community is projected to increase only slightly in the next decade. Consumption in the United States is projected to increase, though at a relatively slow rate of less than one percent (FAO, 2000). Black tea consumption in the countries of the former USSR is projected to increase from 154,000 $\mathrm{mt}$ in 1993-95 to $250,000 \mathrm{mt}$ in 2005 , equivalent to an annual growth rate of 4.5 percent over the period (FAO, 2000).

Import requirements in 2005 are projected at 1.27 million $\mathrm{mt}$, an average annual increase of 2.3 percent from average annual imports in the 1993-95 base period (FAO 2000). Net export availabilities are projected to reach 1.292 million $\mathrm{mt}$ in 2005, an average annual increase of 2.5 percent from the actual exports of $985,000 \mathrm{mt}$ during the base period (FAO, 2000). 
Projections by the FAO suggest that there will be an imbalance in the international black tea demand and supply at current prices. That is, the FAO projects a surplus of exports at current prices. This will result in downward pressure on price that all bulk tea exporters have to face, as there is little product differentiation that exists among exporters' products.

There are several regional entities in different parts of the world that affect tea trade. They are South Asian Association for Regional Cooperation (SAARC), Indo-Lanka Free Trade Agreement (FTA), East African Tea Trade Association (EATTA) and Common Market for Eastern and Southern Africa (COMESA). They have varying degree of influence for world tea trade.

The tea markets addressed in this study are, Sri Lanka (Colombo), three auctions in India (Calcutta, Cochin, Guwahati), Indonesia (Jakarta), Kenya (Mombasa) and Malawi (Limbe). Following is a brief description on tea auctions in each country.

According to Sri Lanka Tea Board (SLTB), Sri Lanka is the third largest tea producing country in the world as of today (SLTB, 2003). It has a 9 percent share of world production. It is one of the world's leading exporters with a share of 19 percent of world export volume
(SLTB, 2003). According to the Central Bank of Sri Lanka (CBSL), the annual average tea price in the Colombo tea auction increased in Sri Lankan Rupee terms but declined in US dollar terms (US\$ 1.50 per kilogram of tea) (CBSL, 2002).

Sri Lankan tea is sold through different marketing channels. They are the Colombo tea auction, private sales, forward contracts and direct sales. But almost 95 percent of tea is sold through the Colombo tea auction. According to SLTB, government has no influence in the price discovery in the auction center and we can infer from SLTB statement that price discovery in the Colombo market is efficient (but this needs further rigorous analysis). The Sri Lankan government does not restrict the amount of tea entering the auction center. There is a tax called cess charged by the SLTB for every kilogram of tea exported. It is 2.50 rupees per kilogram (US\$ 0.025 per kilogram of tea).

According to the India Tea Board, India is the world's largest tea producer and consumer. It produced 870 million kilograms in 1998 (ITB, 2003). Indian tea production is about 30 percent of world production. The major portion is consumed domestically (India-Infoline, 2002). The export market share is about 17 percent globally (India-Infoline, 2002). There are six auctions markets for tea in India. They are Calcutta, 
Coimbatore, Cochin, Guwahati, Coonoor and Siliguri.

Even though the Indian government does not directly influence the price in auction centers, the tea marketing control order requires all the manufacturers to sell 75percent of their tea (excluding exports and packet sales) through auction houses. This guarantees the supply of tea to auction centers. This supply of tea is not exactly what the buyers need and this can have an impact on the price of tea. Furthermore, imports are not allowed for domestic consumption (IndiaInfoline, 2002). These policies introduced by the Indian government on sales of tea can possibly introduce inefficiency in price discovery process in Indian markets.

In the Indonesian tea industry, the main product is black tea and about 80 percent is exported (Tea Auction Ltd, 2003). Indonesia has about 8 percent of world exports (The Tea Council Ltd, 2003).

Tea is a major foreign exchange earner in Kenya. In 1995, the tea industry brought US $\$ 342$ million into the country and Kenya became the largest exporter of black tea in Africa and the third largest in the world. (Tea Auction Ltd, 2003). The majority of the Kenyan tea production is sold through the Mombassa auction. The share of production is about 8 percent globally and the share of exports is about 15 percent (Tea Auction Ltd, 2003). According to the Africa Tea Brokers (ATB), the Kenyan government does not interfere with the price discovery process in the Mombasa auction. However, there are taxes on tea planted acreage and manufacturing. There is no export duty for tea exports. According to the tea board of Kenya, producers have the choice of selling the produce through either the auction center or through private treaty agreements.

Malawi which started growing tea commercially in the 1880 s, now exports over $35,000 \mathrm{mt}$ annually, Malawi has a 4 percent share of world exports (The Tea Council Ltd, 2003).

According to communication with each country's tea auction market and auction conducting agencies, only the Indian government seems to be interfering with the tea price. All non-Indian tea auction markets are trading tea more independently. Yet a systematic analysis is not done to see whether the price discovery in each market is efficient. Therefore, it is important to find out the price dynamics of the tea market and whether the price discovery process is efficient in each market.

\section{Conceptual Framework and Application}

This paper primarily focuses on the use of time series techniques in 
understanding the time related properties of black tea auction market prices around the world and to compare it with the naïve model. Traditional econometric techniques are found to be inadequate when trying to make inferences with time ordered observational data. Prior theory traditionally suggests the explanatory variables that should go into a model. However, theory is developed using the cetris-paribus assumption. When "all other things" are not fixed, as is the case with experimental data, researchers must rely on less "structured" models. Here we use prior theory to suggest variables to be studied, but we rely on empirical patterns in their time sequence to specify explicit relationships among each variable.

\section{Univariate Time Series Model}

Time series analysis studies data observed over a period of time. Each observation is indexed by $t$ in order to keep track of the order of its observation. A key idea behind all time series modeling is that order of observation matters. As an example, let us say that we are observing prices of tea over a period of time. When a new piece of information hits the market in the current time, it moves price away from the most recent price value. This new piece of information is not well defined as a random draw from the historical mean price. Therefore, the historical mean is not a good measure of forecasting the effect of the shock.
Analysis of a single series of data and its movement through time is called univariate analysis. Let $X_{t}$ be a random variable whose value only depends on the past lag values of itself, and values of an error term (this is known as the innovation term in the time series literature). A simple univariate model can be defined as follows:

(1)

$X_{t}=\alpha+\beta_{1} X_{t-1}+\beta_{2} X_{t-2}+\ldots+\beta_{p} X_{t-p}+e_{t}$

Where $\alpha$ is the intercept term and the $\beta$ s are unknown parameters. The term $e$ is the uncorrelated error term. This is assumed to have a zero mean and a variance of $\sigma_{e}^{2}$. We just defined in equation (1) an autoregressive model of order $p$, where $p$ is the number of lags in the model. Stationarity is an important property in time series processes. In general, a time series process is stationary if the mean, variance and co-variance of the series are finite and constant. But if we consider a random walk model: $Y_{t}=Y_{t-1}+e_{t}$, the variance of the series is infinite and the series is not stationary (say $Y_{t}$ is today's price and $Y_{t-1}$ is yesterday's price in the market and the $e_{t}$ is the white noise term). Such series can be differenced once or many times to make them stationary. If the series is differenced once, it is said to be integrated to order 1 (one). That means, $\Delta Y_{t}=\left(Y_{t}-Y_{t-1}\right)$ is a stationary series and integrated of order one; here $Y_{t}$ is an $I(1)$ series. 


\section{Vector Autoregressive Model (Multivariate Time Series Model)}

Constraining oneself to univariate models is generally overly restrictive, as the real world is often times viewed (theoretically) as a set of interacting variables. This leads us to use multivariate models, where many variables and their interactions are considered. Thus vector auto regression (VAR) models have become popular. The VAR is an atheoretic analysis (non-structural analysis) that summarizes the regularities in a set of variables which theory suggests as important (Bessler, 1984). These models are useful in the analysis of observational data; i.e. data that are collected without experimental controls. In structural modeling, we use a pre-determined model suggested through the knowledge of the prior theory and structure. But in VAR modeling the choice of variables studied does not depend on the pre-determined structure, rather on the problem under study and theory, which will be used to study regularities of data. Say we have $m$ endogenous variables, $X_{1}, X_{2}, X_{3} \ldots X_{m}$ under study. The unrestricted VAR can be written as follows:(2)

$\left[\begin{array}{cccc}\alpha_{11} & \alpha_{12} & \ldots & \alpha_{1 m} \\ \alpha_{21} & \alpha_{22} & \ldots & \alpha_{2 m} \\ \vdots & \vdots & \vdots & \vdots \\ \alpha_{m 1} & \alpha_{m 2} & \ldots & \alpha_{m m}\end{array}\right]\left[\begin{array}{c}X_{1 t} \\ X_{2 t} \\ \vdots \\ X_{m t}\end{array}\right]=\left[\begin{array}{c}\delta_{1 t} \\ \delta_{2 t} \\ \vdots \\ \delta_{m t}\end{array}\right]$

Where;

$$
\begin{aligned}
& \alpha_{i j}=1-\alpha_{i j}(1) B^{l}-\alpha_{i j}(2) B^{2}-\cdots \cdots-\alpha_{i j}(k) B^{k} ; i=j \\
& \alpha_{i j}=-\alpha_{i j}(1) B^{1}-\alpha_{i j}(2) B^{2}-\cdots \cdots-\alpha_{i j}(k) B^{k} ; i \neq j
\end{aligned}
$$

Here $B$ is the lag operator, such that $B^{k} X_{t}=X_{t-k}$. The $\alpha_{i j}$ are parameters, unknown, in our case, and to be estimated from observed data. The term $\delta_{i t}$ is the innovation term (error), which is uncorrelated through time but generally correlated in contemporaneous time. That is to say, $\quad E\left(\delta_{i t} \delta_{i t-k}\right)=0 ; k \neq 0$ and $E\left(\delta_{i t} \delta_{i t-k}\right)=\sigma_{i j}^{2} ; k=0$. Lag length, $k$, in equation (2) may be known from prior theory or determined through statistical analysis. The latter usually involves hypothesis testing on lag length, a likelihood ratio test (Sims, 1980) or statistical loss functions (Geweke and Meese, 1981). VAR can be re-written with lags on the right hand on condensed matrix form as:

(3)

$$
X_{t}=\sum_{k=1}^{k} \alpha(k) X_{t-k}+\delta_{t}
$$

Here $\alpha(k)$ is merely a re-write of the $\alpha$ matrix given in equation (2) without the diagonal element. Ones (1) and lag operator (B) is not used. In the last representation (equation (3)), $X_{t}$ is of dimension $m \times 1, \alpha(k)$ is $m x m$ and $\delta_{t}$ is $m x 1$. In constructing the VAR, stationarity of $X_{t}^{\prime}$ 's is assumed. If a 
series is non-stationary, we have to take differences to make it stationary, i.e., $\Delta X_{t}=\left(X_{t}-X_{t-1}\right)$.

\section{Tests of Non-stationarity}

A series is said to be mean nonstationary if the data points are moving away from its historical mean for a long periods of time. In other words, the data are non-mean reverting. Granger and Newbold (1974) used Monte Carlo simulations to show that results from regressions that use such data could be spurious. Non-stationary data may have an infinite variance. This may lead to improper inferences based on the $t$ statistic in estimation and hypothesis testing. Further studies have proved that other traditional statistics such as $F$ distribution and the $R^{2}$ statistic do not have the correct properties in the presence of non-stationary data (Phillips, 1986).

A formal test on non-stationarity is the Dickey-Fuller test (DF). Here we regress the the $\Delta X_{t}=\left(X_{t}-X_{t-1}\right)$ on a constant plus levels lagged period one, $x_{t-1}$.

(4)

$$
\Delta X_{t}=\alpha_{0}+\alpha_{1} X_{t-1}
$$

Our null hypothesis is that the series is non-stationary $\left(\alpha_{l}=0\right)$. When the ordinary least squares (OLS) estimate of $\alpha_{1}$ in equation (4) is significantly negative, we reject the null of series non-stationarity (this means the series is stationary in levels). The $t$-statistic ${ }^{2}$ is the test statistic used in the DF test. The approximate 5 percent critical value estimated using Monte Carlo simulation is -2.89 (say we get a critical value calculated as -4.85 , then we reject the null and conclude that the series is stationary in levels). But sometimes the DF test may suffer from problems of autocorrelation in the estimated residuals (Granger and Newbold, 1986). Then we can use an augmented $\mathrm{DF}$ test (ADF) to sufficiently whiten the residuals. The ADF test has the same null hypothesis and the critical value on estimated $\alpha_{l}$ value in the equation (5) below, but it has an additional set of terms

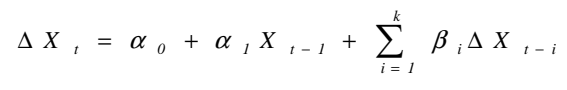

\footnotetext{
${ }^{2} t$-statistic is calculated as the ratio between estimated coefficient and standard error of the estimated coefficient.
} 
In equation (5), $k$ is the lag length selected in order to whiten residuals. We use a loss metric such as Schwarz Loss function to determine $k$.

\section{Computation of the Theil's U statistic}

By calculating the Theil $U$ statistic, we compare our VAR model forecasts against the forecasts generated assuming a random walk model (efficient markets are assumed to have a random walk type of behavior).

The statistic in excess of one means our model did not forecast well compared to the random walk model (the naïve forecast). Theil's $U$ statistic is calculated as follows. To arrive at the Thiel's $U$-statistic, we compute several error statistics, followed by calculating the Thiel's $U$-statistic.

1. Calculate the Sum of Squared Forecast Errors (SSE): $S S E_{t}=\sum_{i=1}^{N_{t}} e_{i t}^{2}$. Where $e_{i t}$ is the actual value minus the predicted value for the dependent variable.

2. Root Mean Error (RME) is calculated: $R M E_{t}=\longdiv { S S E _ { t } / N _ { t } }$

3. Sum of Squared Error No-Change Forecasts

(SSENCF): $\operatorname{SSENCF}_{t}=\sum_{i=1}^{N_{t}} \eta_{i t}^{2} \quad$ where $\eta_{i t}$ is the forecast error if we assume the difference between the dependent variable value assuming the random walk model and the actual observed value.

4. Root Mean Square of the SSENCF:

$R M S N C F_{t}=\longdiv { S S E N C F _ { t } / N _ { t } }$ where

$N_{t}$ is the total number of sample observations. Theil U: $U_{t}=R M S_{t} /$ RMSNCF $_{t}$

\section{Description of Data}

We study weekly prices from December 1999 through June 2002 (a total of 133 data points) for each of the tea auction markets. The data source for tea auction prices is the International Tea Committee (ITC), web summary weekly tea auction data. Prices are quoted in each auction market in different currency denominations. They are as follows: (1) All Indian markets are in Indian rupees; (2) Sri Lankan market is in Sri Lankan rupees; (3) Kenyan, Malawi and Indonesian markets are in US cents.

The study focuses the analysis in two directions, they are, US dollar as the common currency denominator and the other with local currencies of each country as the base. For that, daily averages of exchange rate data were gathered from different sources. Exchange rate data for Sri Lanka, India, Kenya and Indonesia are taken from Oanda Corporation: Internet 
address http://www.oanda.com (accessed on July 17, 2003). Malawi exchange rate data are gathered from the Reserve Bank of Malawi monthly economic review.

Missing auction price data were fixed with data points assuming that they are the same as previous week's data (assumed a random walk model ${ }^{3}$ for the auction market). Regression Analysis for Time Series (RATS) (Doan, 1996) software is used in all analysis.

\section{Analysis and Results}

In Table 1 we discuss the behavior of each price using the mean, standard deviation and the coefficient of variation. We have ranked prices from each auction market over the entire sample period (December 1999 through June 2002).

First we discuss the analysis based on the US dollar as the common currency denominator. Notice that the mean price is highest in the Mombasa (Kenya) market. The lowest is the Limbe (Malawi) market price. Kenya produces a considerable amount of cut-tear-curl (CTC) tea that directly goes into the tea bag industry. Other markets produce relatively less CTC tea compared to
Kenya. Also, it is a known fact that CTC receives a premium price in the world market due to heavy demand for the tea bags (instant tea). That may be a reason why the average price in Kenya is higher than other markets. In terms of the standard deviation (SD) of price, the Kenyan market ranks number one. With respect to the coefficient of variation (CV) it ranks third. This shows how volatile the Kenyan market price is relative to other markets. The Limbe (Malawi) market for tea is a small market and its contribution to world tea exports is very low (please see section 2). That may be a reason why the price is low in this market. The Malawi market has a considerable degree of volatility too. It ranks $4^{\text {th }}$ for SD and $1^{\text {st }}$ for CV. This shows that the Malawi market is the most volatile in terms of $\mathrm{CV}$.

According to the mean, SD and $\mathrm{CV}$ ranks, the Calcutta tea auction has the second highest variation in the prices. The Colombo tea auction ranks third in terms of the mean tea auction price. According to the SD rank $\left(5^{\text {th }}\right.$ position), the Colombo tea auction has moderately volatile prices. The Jakarta tea auction has moderate price volatility in terms of all statistics concerned.

${ }^{3}$ Random walk model assumes the current price is only a function of previous period's price and a white noise term i.e. $p_{t}=p_{t-1}+e_{t}$ 
Table 1: Descriptive Statistics on Prices for Black Tea from Seven Auction Markets, December 1999 through June $2002^{4}$

\begin{tabular}{|c|c|c|c|c|c|c|c|c|}
\hline \multirow[b]{2}{*}{ Market } & \multicolumn{6}{|c|}{ US Dollar } & \multicolumn{2}{|c|}{$\begin{array}{c}\text { Local } \\
\text { currency }\end{array}$} \\
\hline & $\begin{array}{l}\text { Mean } \\
\$ / \mathrm{kg}\end{array}$ & $\begin{array}{l}\text { Mean } \\
\text { Rank }\end{array}$ & $\mathrm{SD}$ & $\begin{array}{c}\text { SD } \\
\text { Rank }\end{array}$ & $\mathrm{CV}$ & $\begin{array}{c}\mathrm{CV} \\
\text { Rank }\end{array}$ & $\mathrm{CV}$ & $\begin{array}{l}\mathrm{CV} \\
\text { Rank }\end{array}$ \\
\hline Calcutta (India) & 1.75 & 2 & 0.28 & 2 & 0.162 & 2 & 0.158 & 2 \\
\hline Guwahati(India) & 1.56 & 4 & 0.21 & 3 & 0.135 & 4 & 0.132 & 4 \\
\hline $\begin{array}{l}\text { Cochin (India) } \\
\text { Colombo (Sri }\end{array}$ & 1.15 & 5 & 0.12 & 7 & 0.101 & 6 & 0.083 & 6 \\
\hline $\begin{array}{l}\text { Lanka) } \\
\text { Jakarta }\end{array}$ & 1.69 & 3 & 0.15 & 5 & 0.088 & 7 & 0.079 & 7 \\
\hline $\begin{array}{l}\text { (Indonesia) } \\
\text { Mombasa }\end{array}$ & 1.09 & 6 & 0.14 & 6 & 0.128 & 5 & 0.112 & 5 \\
\hline (Kenya) & 1.89 & 1 & 0.29 & 1 & 0.152 & 3 & 0.143 & 3 \\
\hline Limbe (Malawi) & 0.98 & 7 & 0.16 & 4 & 0.163 & 1 & 0.250 & 1 \\
\hline
\end{tabular}

Now we look at the price variation in each market when prices are considered in local currency terms. In this case mean and SD are not very good measures to compare markets for price volatility, because now we have different currency bases for each market. The $\mathrm{CV}$ is a better

measure in this case. The Malawi market ranks number one in price volatility and the Sri Lankan market has the least price volatility in terms of $\mathrm{CV}$. Kenya ranks number three in volatility with respect to local currency analysis. The weakness of using the above

${ }^{4}$ Observed data are weekly average prices received in each tea auction market. On the left hand side of the table we discuss the summary statistics of dollar-converted data (Prices are quoted here in US \$/kilogram of black tea. Kenyan, Malawi and Indonesian markets trade in US dollar terms, and other markets are in local currencies). On the right hand side column of the table we discuss the summary statistics from auction prices in local currency terms.

The entry "Mean" refers to the mean price quoted in each market in the sample period. "Mean Rank" column refers to the ranking based on the mean price in the market. The acronym SD stands for the standard deviation of the prices in each market over the sample period. The term "SD Rank" is the column that ranks the auction market price based on the standard deviation. The column headed CV refers to the coefficient of variation, calculated as the standard deviation divided by the mean for each market price. The CV Rank refers to the ranking based on the coefficient of variation. The highest rank is 1 and the lowest rank is 7 . 
summary statistics in the analysis is that they do not incorporate the time series properties of the underlying price series.

\section{Time Series Properties}

Here we explain two sets of graphs (see Figure 1 and Figure 2) drawn for price in levels of each tea auction market. In Figure 1 we have shown the price movement in each market taking the US dollar as the currency denominator. In Figure 2 we have drawn the graphs considering the local currency in each country.

The visual observations of each market reveal the following information. In Figure 2, two of the Indian markets, namely Calcutta and Guwahati, do not have any noticeable time trend. It appears as if prices from these two markets are bouncing around their historical means. The Cochin market has a little time trend, but it is minor when compared to the time trending in other markets. Even in the dollarconverted graph, Indian markets show a similar movement of prices. Since there is no big difference in those two graphs in the Indian market we tentatively infer that the Indian Rupee might have been stable with respect to the US dollar at least in the time period concerned in this study. That is why whether we measure in Rupee or in dollar terms, we observe a similar movement in prices.
The Sri Lankan tea price (Colombo auction market) has an upward trend in Sri Lankan Rupee terms. We observe a downward trend in the Colombo auction price in terms of the US dollar. The Sri Lankan Rupee appears to have devalued against the US dollar faster toward the latter part of the sample period. The Sri Lankan Rupee is free floated against the US dollar and the monetary authority has allowed it to devalue to promote exports. Within the sample period concerned the rupee has devalued considerably. That may be the reason that in terms of the US dollar the Colombo auction market has a downward trend toward the end of the sample period.

Tea prices in Indonesia (Jakarta) show a downward trend in terms of the US dollar (note that the Jakarta tea auction trades in US dollars). The graph shows that the tea prices in Jakarta are decreasing in dollar terms. In the local currency terms, tea prices in Jakarta have an upward trend. This shows that the Indonesian Rupiah has devalued against the US dollar over the sample period. Even though the Indonesian tea producer gets a lower price for tea in terms of US dollars, once converted into Rupiah they get a high price.

The Kenyan auction market price has a similar downward trend in both the dollar and Kenyan Shillings 

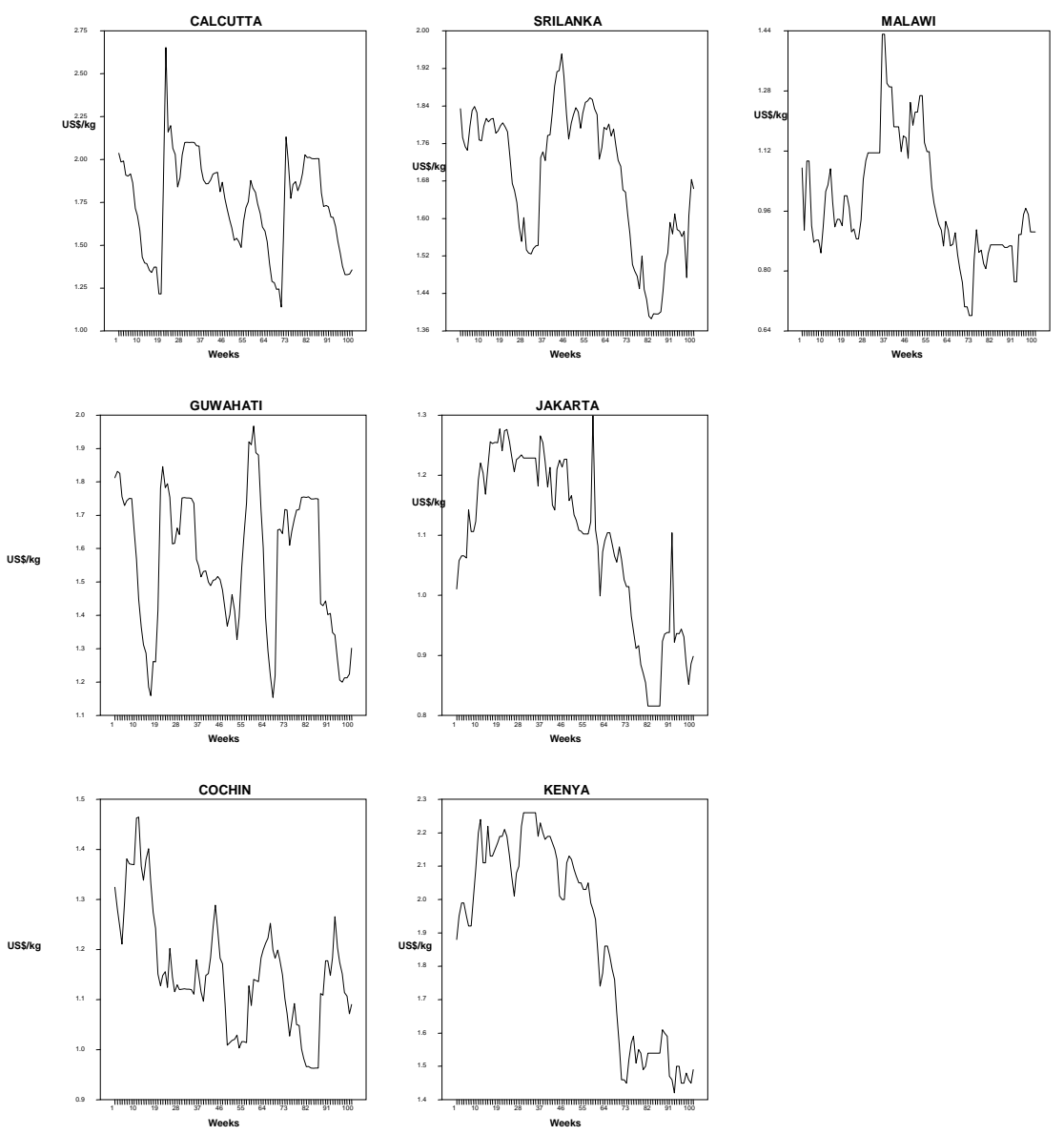

Figure 1: Black Tea Auction Price in Levels in Seven World Auction Centers (December 1999 through June 2002) in US Dollar Terms ${ }^{5}$

${ }^{5}$ Note that auction centers in Jakarta, Kenya and Malawi trade in US dollar terms. Rest of the markets does trade in their local currencies. In this plot all prices are converted into US dollar terms. Note that horizontal axis in all graphs are number of Weeks and vertical axis in all graphs are in US $\$ / \mathrm{kg}$. 

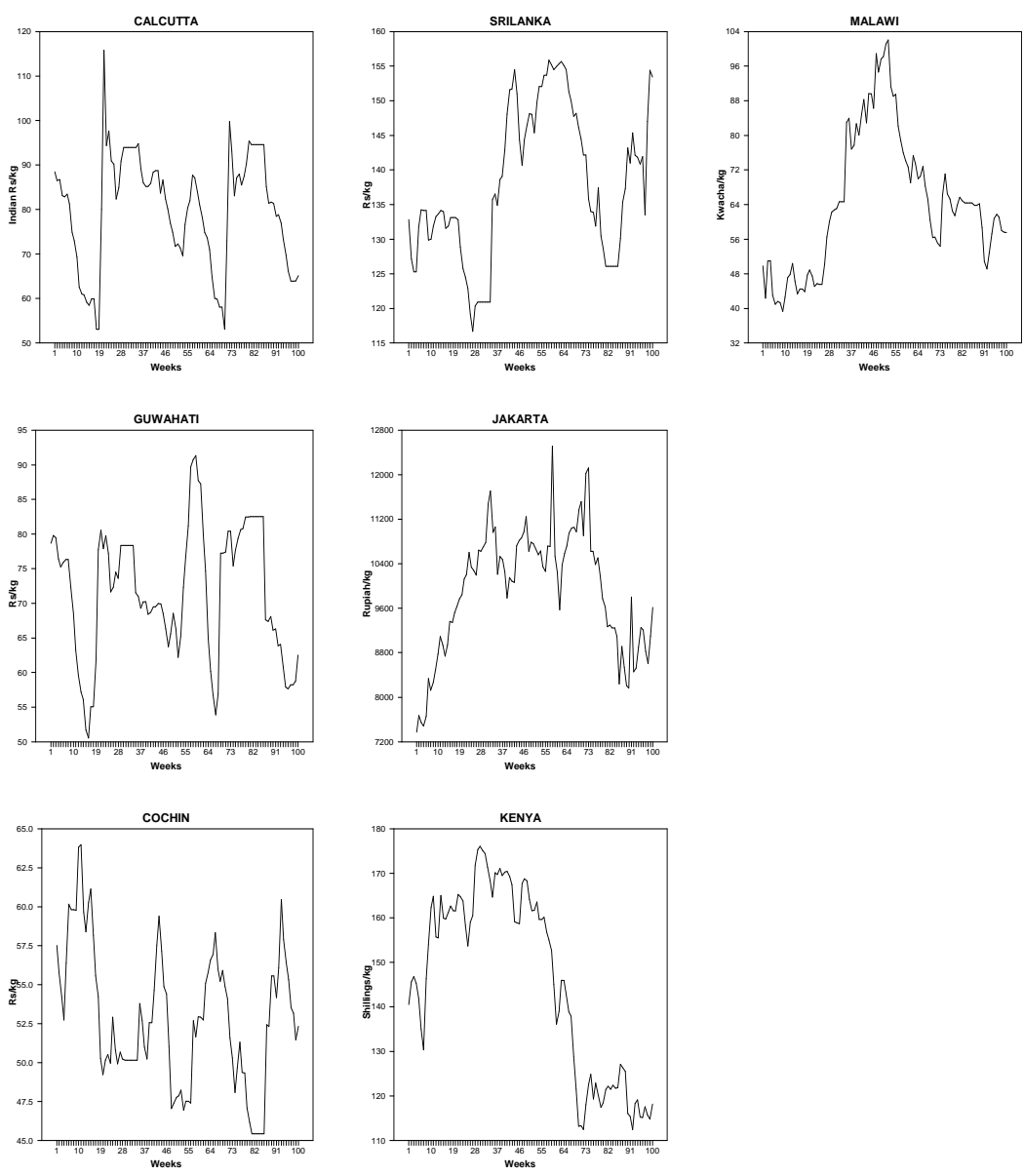

Figure 2: Black Tea Auction Price in Levels in Seven World Auction Centers (December 1999 through June 2002) in Local Currencies ${ }^{6}$

${ }^{6}$ Note that India trades in Indian rupees and Sri Lanka in Sri Lankan rupees. Indonesian market price is converted into Indonesian Rupiah, Kenyan market price is converted to Kenyan Shillings and Malawi market price is converted into Malawi Kwacha. Note that all horizontal axis are in Weeks. Vertical axis for Calcutta, Guwahati and Cochin are in Rs/kg, for Sri Lanka in Rs/kg, Jakarta in Rupiah/kg, Kenya in Shillings/kg and Malawi in Kwacha/kg. 
terms (there are small differences in peaks and troughs). This shows that the Kenyan currency has not changed much during the sample period. However, it is worth showing that price at the Kenyan auction center decreases over the time period and hits a very low level towards the end of the sample period. This means that the Kenyan tea grower is not experiencing a lucrative period as prices are falling considerably.

Tea prices in Malawi (Limbe auction center) increased up until the middle of the sample period and then started to fall both in US dollar terms and Malawi Kwacha terms. The decrease in price in US dollar terms is more intense than the local currency terms. This shows that the Kwacha is devaluing against the dollar, but at a slower rate. The money that the local farmer earns in terms of Kwacha is decreasing and this discourages the Malawi tea growers.

Note that there is no exchange rate risk in price discovery in Jakarta, Kenya and Malawi markets, as these markets are held in US dollar terms. Nevertheless, the local producer gets paid in local currency. Whether this amount is increasing or decreasing over time is determined through the purchasing power of each currency.

Except from the plots from three Indian markets, we suspect the mean non-stationary property in prices in all other auction markets. A more rigorous analysis of the time series properties is given below. We offer tests on unit root behavior for each market in the following section.

Table 2 gives the result from the Dickey-Fuller (DF) and the Augmented Dickey-Fuller (ADF) tests for dollar converted and local currency data on each series. The null hypothesis is that prices from all tea auction markets are mean nonstationary. The statistics presented on the table have a 5 percent critical value of -2.89 . Under both the DF and ADF tests, we reject the null for calculated statistics less than this 5 percent level.

In the dollar-converted analysis, the DF test tells us that all but the Cochin market is mean nonstationary in levels. The ADF shows that all Indian markets are mean stationary in levels and the remainder of the markets are mean nonstationary in levels. In the local currency analysis, all but the Indonesian market is mean nonstationary in levels. The ADF shows that all Indian markets again are mean stationary in levels and the rest of the markets are mean nonstationary in levels. As residuals from these markets are better behaved under the ADF (we have made the residuals "white" by augmenting the DF test with lags of the dependent variable), we suggest the use of results from augmented tests. The tests suggest that price in 
Table 2: Tests of Non stationary on Price from Seven Tea Auction Markets, December 1999 through June 2002

\begin{tabular}{|c|c|c|c|c|c|c|}
\hline \multirow[b]{2}{*}{ Tea auction center } & \multicolumn{3}{|c|}{ US Dollar $^{7}$} & \multicolumn{3}{|c|}{ Local Currency $^{8}$} \\
\hline & $\begin{array}{c}\mathrm{DF}^{9} \\
\text { t-statistic }\end{array}$ & $\begin{array}{c}\mathrm{ADF} \\
\mathrm{t} \text {-statistic }\end{array}$ & $\mathrm{K}^{10}$ & $\begin{array}{c}\text { DF } \\
\text { t-statistic }\end{array}$ & $\begin{array}{c}\mathrm{ADF} \\
\text { t-statistic }\end{array}$ & $\mathrm{k}$ \\
\hline Calcutta (India) & -2.59 & -3.23 & 1 & -2.70 & -3.30 & 1 \\
\hline Guwahati (India) & -2.04 & -4.20 & 3 & -2.21 & -4.24 & 3 \\
\hline Cochin (India) & -3.42 & -3.48 & 1 & -2.39 & -3.47 & 1 \\
\hline Colombo (Sri Lanka) & -1.47 & -1.58 & 1 & -1.32 & -1.41 & 1 \\
\hline Jakarta (Indonesia) & -1.42 & -0.92 & 1 & -2.94 & -2.20 & 1 \\
\hline Mombasa (Kenya) & -0.72 & -0.89 & 1 & -0.67 & -0.86 & 1 \\
\hline Limbe (Malawi) & -1.71 & -1.81 & 1 & -1.45 & -1.61 & 1 \\
\hline
\end{tabular}

the non-Indian markets behave as a random walk: $P_{t}=P_{t-1}+e_{t}$, where $e_{t}$ is a white noise (uncorrelated) innovation.

As we are studying the prices as they evolve in the market through time, we fully expect that they will individually look much like a random walk (Samuelson, 1965). That is, from the results on the Table 2, each non-Indian market behaves such that new information perturbs price away from the most recent value and not as a perturbation from the historical mean. This is not true with respect to the three Indian

${ }^{7}$ riginal currencies used to trade in auction markets.

1. Indian markets-Indian Rupees.

2. Sri Lankan market-Sri Lankan Rupees.

3. Indonesian, Kenyan and Malawi markets- US dollar.

${ }^{8}$ ocal currencies in each market:

1. Indian markets-Indian Rupees.

2 .Sri Lankan market- Sri Lankan Rupees.

3. Indonesian market-Rupiah.

4. Kenyan market-Shillings.

5. Malawi market-Kwacha.

${ }^{9} \mathrm{~F}$ is the Dickey Fuller test and ADF is the Augmented Dickey Fuller Test.

${ }^{10}$ Note that $k$ is the lag length and is determined through the Schwarz-Loss Metric (we take the lag length that has the minimum Schwarz-Loss value). 
markets. In levels, the Indian markets are mean stationary. That means the new information perturbs price away from the historical mean and not from the most recent value. Prices in the 3 Indian markets are not generated through random walk like behavior. The other 4 markets are mean non-stationary according to the unit root tests. The 3 Indian markets are taken out of the analysis, as price from these markets are not efficient (not weak-form efficient). The word "efficient" is used to suggest that the best prediction of price in India in period $t+1$ is something different from the price in period $t$ (its historical mean price is a useful statistic for next period's price). This result appears not to hold for the four non-Indian markets. Here we cannot reject the random-walk hypothesis. Following Fama (1970), we say these four non-Indian markets are efficient in terms of price discovery.

From the results of the ADF tests above we conclude that four tea auctions, Sri Lanka (Colombo), Indonesia (Jakarta), Kenya (Mombasa) and Malawi (Limbe) are individually non-stationary in both dollar and local currency analysis. Our next step is to find out whether the data are co-integrated, before we try to develop a VAR.
According to Table 3 and Table 4 , we reject the null hypothesis of the presence of any co-integrating vectors. Therefore, there is no cointegration in dollar converted and local currency data. Now we concentrate on building a VAR for the auction market price.

To develop the VAR and to identify the time series properties, first we need to make the data series stationary (the need for making the data series stationary is discussed extensively in section 3). For that we take the first differences of each data series. We develop two VARs, one for each dollar converted series and local currency series.

We used the Schwarz Loss $(\mathrm{SL})^{11}$ function to determine the number of lags in the VAR. We select the lag length that gives the minimum SL value. According to that the lag length in our VAR in dollar converted series and local currency data series is one. Therefore, we take one lag of first differenced data. The following abbreviations are used for each market: Colombo (Sri Lanka) (SLA), Jakarta (Indonesia) (INA), Mombasa (Kenya) (KEN), and Limbe (Malawi) (MAL). The $\square$ refers to the first difference of a series, such as $\Delta S L A_{t}=\left(S L A_{t}-S L A_{t-1}\right)$.

${ }^{11} S L=\ln |\Gamma|+(m x k)(\ln T) T$ Where $\Gamma$ is the error covariance matrix estimated with $\mathrm{k}$ regressors in each equation, $\mathrm{T}$ is the total number of observations on each series, || denotes the determinant operator, and $\ln$ is the natural logarithm (Geweke and Meese, 1981). 
Table 3: Tests of Cointegration between Prices from Four Tea Auction Markets (December 1999 through June 2002) ${ }^{12}$

Dollar Converted Data

\begin{tabular}{crccccc}
\hline $\mathrm{R}$ & $\mathrm{T} *$ & $\mathrm{C}(5 \%) *$ & $\mathrm{D} *$ & $\mathrm{~T}$ & $\mathrm{C}(5 \%)$ & $\mathrm{D}$ \\
\hline & & & & & & \\
$=0$ & 51.688 & 53.423 & $\mathrm{~F} \#$ & 54.516 & 47.208 & $\mathrm{R}$ \\
$<=1$ & 19.947 & 34.795 & $\mathrm{~F}$ & 28.006 & 29.376 & $\mathrm{~F}$ \\
$<=2$ & 5.410 & 19.993 & $\mathrm{~F}$ & 9.836 & 15.340 & $\mathrm{~F}$ \\
$<=3$ & 0.840 & 9.113 & $\mathrm{~F}$ & 0.947 & 3.841 & $\mathrm{~F}$ \\
\hline
\end{tabular}

F\# is the first fail to reject situation that suggest the presence of no cointegration among 4 tea auction markets.

Table 4: Tests of Cointegration between Prices from Four Tea Auction Markets (December 1999 through June 2002) Local Currency Data

\begin{tabular}{crrrrrr}
\hline $\mathrm{R}$ & \multicolumn{1}{c}{$\mathrm{T}^{*}$} & $\mathrm{C}(5 \%)^{*}$ & $\mathrm{D}$ & \multicolumn{1}{c}{$\mathrm{T}$} & $\mathrm{C}(5 \%)$ & $\mathrm{D}$ \\
\hline$=0$ & 33.313 & 53.423 & $\mathrm{~F} \#$ & 44.469 & 54.516 & $\mathrm{~F}$ \\
$<=1$ & 12.677 & 34.795 & $\mathrm{~F}$ & 23.718 & 28.006 & $\mathrm{~F}$ \\
$<=2$ & 5.726 & 19.993 & $\mathrm{~F}$ & 11.931 & 9.836 & $\mathrm{R}$ \\
$<=3$ & 0.704 & 9.113 & $\mathrm{~F}$ & 3.907 & 0.947 & $\mathrm{R}$ \\
\hline
\end{tabular}

$\mathrm{F} \#$ is the first fail to reject situation that suggest the presence of no cointegration among 4 tea auction markets.

Lagged one period of first the plus sign from left shows the differences is shown in the $3^{\text {rd }}$ matrix innovation term for each series.

from the left. The final matrix after

\footnotetext{
${ }^{12} \mathrm{R}$ is the number of co-integrating vectors (it runs from being equal to zero through equal or less than $3 . \mathrm{T}^{*}$ is the calculated trace test for constant inside the cointegrating space, associated with the number of co-integrating vectors in the lefthand-most column. $\mathrm{C}(5 \%) *$ is the table value of the statistic at $95 \%$ significance level. $\mathrm{D}$ is the decision to reject or fail to reject the null hypothesis of presence of cointegrating vectors. Following Johansen (1992), we stop testing at the first failure to reject the null, starting at the top of the table and moving sequentially across from left to right and from top to the bottom. R stands for reject the above null hypothesis. T, $\mathrm{C}(5 \%)$ and $\mathrm{D}$ without the asterisk means the test results for the discovery of cointegrating vectors where the constant outside the co-integrating space. The critical values are taken from Table B.2 (within) and Table B.3 (outside) in Hansens and Juselius (1995, p. 80-81).
} 
The estimated VAR model for dollar converted data series is as follows ${ }^{13}$ :

$$
\left[\begin{array}{c}
\Delta S L A \\
\Delta I N A \\
\Delta K E N \\
\Delta M A L
\end{array}\right]=\left[\begin{array}{ccccc}
-0.00054 & 0.119 & 0.103 & 0.069 & -0.031 \\
(-0.128) & (1.179) & (1.118) & (0.783) & (-0.469) \\
-0.0013 & 0.339 & -0.279 & 0.049 & -0.036 \\
(-0.297) & (3.232) & (-2.909) & (0.534) & (-0.523) \\
-0.0036 & -0.008 & -0.119 & 0.229 & 0.118 \\
(-0.735) & (-0.064) & (-1.104) & (2.241) & (1.515) \\
0.00023 & -0.116 & -0.113 & 0.152 & -0.034 \\
(0.036) & (-0.754) & (-0.802) & (1.139) & (-0.339)
\end{array}\right]\left[\begin{array}{c}
1 \\
\Delta S L A_{t-1} \\
\Delta I N A_{t-1} \\
\Delta K E N_{t-1} \\
\Delta M A L_{t-1}
\end{array}\right]+\left[\begin{array}{l}
\varepsilon_{1 t} \\
\varepsilon_{2 t} \\
\varepsilon_{3 t} \\
\varepsilon_{4 t}
\end{array}\right]
$$

The estimated VAR model for local currency data series is as follows:

$$
\left[\begin{array}{c}
\Delta S L A \\
\Delta I N A \\
\Delta K E N \\
\Delta M A L
\end{array}\right]=\left[\begin{array}{ccccc}
0.253 & 0.097 & 0.00027 & 0.043 & -0.0031 \\
(0.729) & (0.959) & (0.385) & (0.529) & (-0.037) \\
21.608 & 15.836 & -0.282 & -0.778 & -6.533 \\
(0.439) & (1.111) & (-2.816) & (-0.068) & (-0.546) \\
-0.227 & -0.075 & -0.00039 & 0.181 & 0.220 \\
(-0.529) & (-0.602) & (-0.453) & (1.806) & (2.112) \\
0.195 & -0.102 & -0.00032 & 0.051 & 0.016 \\
(0.458) & (-0.820) & (-0.369) & (0.513) & (0.152)
\end{array}\right]\left[\begin{array}{c}
1 \\
\Delta S L A_{t-1} \\
\Delta I N A_{t-1} \\
\Delta K E N_{t-1} \\
\Delta M A L_{t-1}
\end{array}\right]+\left[\begin{array}{c}
\varepsilon_{1 t} \\
\varepsilon_{2 t} \\
\varepsilon_{3 t} \\
\varepsilon_{4 t}
\end{array}\right]
$$

Most of the coefficients are own lag one period and lag one statistically not significant at 95 period price of the Sri Lankan percent confidence level (according market. New information discovered to the $t$-statistics in parentheses) for in the Kenyan market today is mainly both analyses. However, in the affected by the Kenyan market price dollar-converted data series, last period (lagged one period) (see coefficients associated with INA on the t- statistic is 2.241). In the local INA and SLA lagged one period are statistically significant at the 95 percent level ( $t$-statistics -2.909 and 3.232 respectively). This shows that the information (price) discovered in INA today is primarily affected by its currency data series only the coefficient associated with the Indonesian market on its own lag one period is statistically significant at the 95 percent level (the $t$-statistics is $-2.816)$. The coefficients of the VAR

\footnotetext{
${ }^{13} t$-statistics are in parenthesis. The constant is in the autoregressive matrix (it is the first column of the autoregressive matrix).
} 
do not seem to be much informative and difficult to interpret. Therefore, one can develop the moving average representation of the VAR. This is not dealt in this paper.

If a market price discovery process can be better explained through a VAR model, it is said to be semi-strong-form efficient. On the other hand, if the price discovery process can be explained through a random-walk model, these markets are said to be weak-form efficient.

We initially collected 133 weekly data points (December 1999 through June 2002). For the purpose of model estimation we used only 100 data points and saved the remainder of our sample (33 weekly data points) to examine the power of the model through forecasting. We compared the forecasting ability of the model using the Theil's $U$-statistic (Doan, 1996). Based on the models discussed above we forecast the final 33 data points. Our forecasting operation is recursive for one-period, two-periods, up to five periods ahead. At each origin, we re-estimate the model and forecast up to five steps ahead. From these and actual data (data we saved without using to estimate the VAR), we compute the Theil's $U$-statistic. Theil's $U$-statistic is calculated as the ratio between the root mean square of the errors of forecasts using the vector auto regression model and the root mean square of the errors of forecasts using the random walk model.

By calculating the Theil $U$ statistic, we compare our VAR model forecasts against the forecasts generated assuming a random walk model (efficient markets are assumed to have a random walk type of behavior). The statistic in excess of one means our model did not forecast well compared to the random walk model (the naïve forecast). Tables 5 and 6 explain the forecast performance of VAR models for each market.

According to the Theil $U$ statistic, the VAR model developed using the dollarconverted data forecasts relatively well for Sri Lankan and Malawi markets for two steps ahead forecasts. Forecast errors from the VAR are larger relative to the random walk model for rest of the markets. In the local currency series, the VAR model forecasts relatively well for the Malawi market for one step ahead. For the rest of the markets, the forecast errors from the VAR are large relative to the naïve model forecasts. 
Table 5: Theil's U-Statistic ${ }^{14}$ to Compare the Forecast Performance of VAR in Different Markets, US Dollar Converted Data

\begin{tabular}{cccccc}
\hline Step $^{15}$ & Sri Lanka & Indonesia & Kenya & Malawi & $\begin{array}{c}\text { Number of } \\
\text { Observations }^{16}\end{array}$ \\
\hline 1 & 0.995 & 0.999 & 1.051 & 0.994 & 32 \\
2 & 1.003 & 1.027 & 1.064 & 1.005 & 31 \\
3 & 0.992 & 1.032 & 1.071 & 1.012 & 30 \\
4 & 0.993 & 1.062 & 1.083 & 1.017 & 29 \\
5 & 0.989 & 1.063 & 1.115 & 1.022 & 28
\end{tabular}

Table 6: Theil's $U$-Statistic to Compare the Forecast Performance of VAR in Different Markets, Local Currency Data

\begin{tabular}{cccccc}
\hline Step & Sri Lanka & Indonesia & Kenya & Malawi & $\begin{array}{c}\text { Number of } \\
\text { Observations }\end{array}$ \\
\hline 1 & 1.016 & 1.033 & 1.052 & 1.003 & 32 \\
2 & 1.036 & 1.053 & 1.062 & 0.989 & 31 \\
3 & 1.041 & 1.054 & 1.064 & 0.994 & 30 \\
4 & 1.051 & 1.073 & 1.069 & 0.995 & 29 \\
5 & 1.063 & 1.069 & 1.099 & 0.996 & 28 \\
\hline
\end{tabular}

Discussion and Conclusions

We have studied weekly black tea auction prices from eight auction markets over the period December 1999 through June 2002. We performed the analysis in two ways; we used the US dollar as the common currency denominator and we used the local currencies in each country. Our results show for both sets of analyses, prices from three Indian markets (Calcutta, Guwahati and Cochin) are stationary and prices from other markets (Sri Lanka, Indonesia, Kenya and Malawi) are non-stationary. Therefore, prices from Indian auction markets are tied to a particular historical mean and prices from the other markets are not tied to any historical mean.

\footnotetext{
${ }^{14}$ Theil's $U$-statistic is calculated as the ratio between the root mean square of the errors of forecasts using the vector auto regression model and the root mean square of the errors of forecasts using the random walk model.

${ }^{15}$ Steps: this is the number of steps ahead the model forecasts.

${ }^{16}$ Number of Observations: this is the number of observations available for each step ahead forecast.
} 
We conclude that the three Indian markets are not efficient in terms of price discovery. That is to say, if a market is efficient, any new information discovered in the market perturbs price from its most recent level and not as a random draw from its historical mean. This is the efficient market hypothesis. Since Indian market prices are tied to their historical means, according to the efficient market hypothesis, they are not efficient in terms of price discovery. This takes us to the conclusion that the rest of the markets may be efficient, as their prices are not tied to their historical means. We continued the study of market prices from Sri Lanka, Indonesia, Kenya and Malawi. Our results, from both dollar terms and local currency terms, show that these four markets are not tied together in any long run co-integration relationship. This means that there is no "long run" predictable relationship holding these four markets together. In terms of efficiency, such a finding is supportive of pricing efficiency, since it would not be possible to generate predictable returns from knowledge of these "public prices".

We can draw several implications out of our study for different markets participating in black tea trade. The Indian markets show clear evidence of market inefficiency. Tea producers in other producing countries can receive new and valuable information on tea prices in these other markets. The models developed here can be used to forecast the tea prices reasonably well. Theil's $U$-statistic for several markets is found to be below 1.0 for 32 one-step-ahead forecasts. This suggests only small gains relative to the most recent observed price. Buyers (exporters) at the auctions can obtain relevant information coming from other tea markets to the respective price in the auction that they intend buying tea. Implications related to diversification in buying have not been explored, but do seem to be non-trivial. Since the tea markets are efficient (at least the four markets under study), government policy maker need not do much here; rather they should not intervene in the market and distort the price.

Now that we have identified that price discovery in all non-Indian markets under study are efficient, further analysis combining price discovery and market integration can be carried out. Furthermore, the variance co-variance matrix of innovations (error terms) can be developed from the VAR model and can be used to study the contemporaneous and long run behaviour of auction markets.

\section{References}

Bessler, D. A. (1984). Relative Prices and Money: A Vector Autoregression on Brazilian Data. American Journal of 
Agricultural Economics. 66:25-30.

Central Bank of Sri Lanka. (2002). Annual Report. Colombo. Central Bank of Sri Lanka. 83-96.

Doan, T. A. (1996). Regression Analysis for Time Series (RATS). Version 4, Esima, Evanston, IL.

Fama, E. F. (1970). Efficient Capital Markets: A Review of Theory and Empirical Work. Journal of Finance. 25:383417.

FAO. (2000). Tea Projections. Internet address: http://www.fao.org/es/escles celescr /tea/teae.htm (accessed on June 14, 2003).

Geweke, J. and R. Meese.(1981). Estimating Regression Models of Finite but Unknown Order. International Economic Review. 22:55-70.

Granger, C.W.J. and P. Newbold. (1974). Spurious Regression in Econometrics. Journal of Econometrics. 2:111-120.

Forecasting Economic Time Series. (1986). Academic Press, New York, second edition.

Hansen, H. and K. Juselius. (1995). CATS in RATS: Co- integration Analysis of Time Series. Estima, Evanston, IL.

India-Infoline. (2002). Tea. India Info Line Sector Database. Internet address: http://www.indiainfoline.com /sect/teil/ch04.html (accessed on June 26, 2003).

ITB (2003). Tea Economics. India Tea Board. Internet address: http://64.95.196.106/econom ics.html (accessed on July 14, 2003).

Johansen, S. (1992). Determination of Co-integration Rank in the Presence of a Linear Trend. Oxford Bulletin of Economics and Statistics. 54:383-397.

Phillips, P.C.B. (1986). Understanding Spurious Regressions in Econometrics. Journal of Econometrics. 33:311-340.

Samuelson, P. (1965). Rational Theory of Warrant Pricing. Industrial Management Review. 6:13-32.

Sims, C. A. (1980). Macroeconomics and Reality. Econometrica. 48:1-48.

SLTB. (2003).Ceylon Tea. Internet address: http://www.pureceylontea. com /srilankatea.htm 
(accessed on July 14, 2003).

Tea Auction Ltd. (2003) .Tea and Indonesia.Global Tea. Internet address: http://www.teauction.com/ industry/indonestea.asp (accessed on June 26, 2003).

The Tea Council Ltd. (2003). Other Tea Producers. Internet address: http://www.tea.co.uk/tGlor iousT/other.htm (accessed on June 26, 2003). 